\title{
A Inteligência Artificial e a disputa por diferentes caminhos em sua utilização preditiva no processo penal
}

\author{
The Artificial Intelligence and the dispute for different \\ ways in its predictive use in the criminal process
}

\author{
Rodrigo Régnier Chemim Guimarães ${ }^{\mathbf{1}}$ \\ Universidade Positivo - Curitiba/Paraná \\ rrchemim@hotmail.com \\ http://lattes.cnpq.br/3509382891487960 \\ Dhtt://orcid.org/0000-0001-7378-4553
}

\begin{abstract}
Resumo: O artigo explora a disputa entre dois modelos globais em torno da aceitação da inteligência artificial para pesquisas preditivas de decisões de juízes e tribunais, com especial enfoque no âmbito do processo penal. Enquanto nos Estados Unidos a pesquisa é livre e vem se desenvolvendo, na França houve criminalização do comportamento de quem se utilizar de decisões judiciais para tanto. Considerando a delicada cooperação entre peritos em processo penal e engenheiros do conhecimento na construção dos algoritmos que irão ensinar a máquina nas pesquisas preditivas, qual dos dois caminhos seria o adequado? $\mathrm{A}$ disparidade de premissas interpretativas no processo penal coloca em risco possíveis construções silogísticas que possam partir de entimemas? O uso de inteligência artificial na análise preditiva de decisões processuais penais viola ou assegura garantias constitucionais? Levando em conta essas questões, o artigo pretende avaliar se o modelo liberal norte-americano seria a melhor opção, sem olvidar de alguns alertas já identificados pela Comissão Europeia para a eficácia da Justiça, em sua recente "Carta Ética Europeia de Utilização da Inteligência Artificial nos Sistemas Judiciários e seu Entorno", notadamente quanto aos riscos
\end{abstract}

1 Doutor em Direito de Estado pela UFPR. Professor Titular de Direito Processual Penal na graduação e no Mestrado Profissional em Direito na Universidade Positivo, em Curitiba, Paraná. Procurador de Justiça no Ministério Público do Estado do Paraná. 
de prevalências de preconceitos que possam estruturar equivocadamente as pesquisas preditivas e seus resultados.

Palavras-Chave: inteligência artificial; predição; silogismos; processo penal.

ABSTRACT: The article explores the dispute between two global models about the acceptance of artificial intelligence to carry out predictive research around judges and courts, with special focus on criminal procedures. While in the United States research is free and has been developing, in France there has been recent criminalization of the behavior of those who use judicial decisions to do so. Given the delicate cooperation that must exist between experts in criminal procedure and knowledge engineers in the selection and construction of the algorithms that will teach the machine for the preparation of the predictive research, which one would be appropriate? The disparity of interpretative premises in the criminal process put in risk some possible syllogistic constructions that may arise from entimemas? Does the use of artificial intelligence in predictive analysis of criminal procedural decisions violate or ensure constitutional guarantees? Taking these issues into account, the article aims to evaluate whether the US liberal model would be the best option, without forgetting some alerts already identified by the European Comission for the effectiveness of Justice in its recent "European Ethical Charter on the Use of Artificial Intelligence in Judicial Systems and its Environment", notably regarding the risks of prevalence of prejudices that may misrepresent predictive research and its results.

KEYwORDS: Artificial Intelligence; prediction; syllogisms; criminal proceedings.

SUMÁRIO: Introdução; 1. O "jogo da imitação" e a divisão da inteligência artificial em "fraca" e "forte"; 2. Algoritmos e dificuldades operacionais da inteligência artificial; 3. Paradigmas filosóficos estruturantes do conhecimento; 4. Algoritmos e os silogismos aristotélicos; 5. Potenciais entimemas na elaboração de sistemas peritos: um problema a ser considerado no emprego da inteligência artificial em análises preditivas; 6. O modelo de pesquisa norte-americano; 7. A reação francesa. 8. O ponto de equilíbrio da Comissão Europeia para a Eficácia da Justiça - CEPEJ: entre a filosofia crítica de Eric Sadin e o otimismo matemático de Cristian Calude e Giuseppe Longo; Considerações Finais; Referências. 


\section{INTRODUÇÃO}

Ainda que as experiências pioneiras e posteriores a Alan Turing no uso da inteligência artificial datem já de mais de meio século, foi apenas quando de sua conjugação com a facilitação do acesso à rede mundial de computadores, nos últimos vinte anos, que ela ganhou impulso decisivo a ponto de vir se inserindo paulatinamente no cotidiano das pessoas. Seu emprego hoje facilita a pesquisa sobre qualquer assunto, cataloga preferências, organiza perfis de consumo, seleciona propagandas, difunde ideias, formata e pasteuriza opiniões, promove censuras, direciona debates e até mesmo realiza ações concretas no mundo físico, a exemplo de acender e apagar a luz, ligar e desligar um aparelho, pesquisar uma música, o clima ou qualquer outro assunto. $\mathrm{O}$ avanço é de tal ordem que uso da inteligência artificial permite estabelecer um diálogo programado entre a máquina e o ser humano, como se dá com a assistente virtual Alexa, da empresa Amazon e suas correlatas. A sociedade já não parece mais ser capaz de se desenvolver sem o emprego da inteligência artificial. É uma tecnologia que veio para ficar e se expandir em modo que há poucos anos somente era imaginado em livros ou filmes de ficção científica.

Compreender como tudo isso impacta no direito processual penal e como será possível usufruir da inteligência artificial na melhoria do desempenho processual é inevitável e urgente. Já se sabe que são inúmeras as possibilidades de uso da inteligência artificial no processo penal, desde o consolidado auxílio em pesquisa jurisprudencial, passando pela produção e valoração probatórias, elaboração de petições e juízos de admissibilidade de recursos extraordinários ${ }^{2}$. Uma delas em particular vem gerando não apenas controvérsia, mas até mesmo providência legislativa: trata-se da função preditiva que o uso da inteligência artificial pode promover em torno das decisões judiciais no âmbito processual.

São dois os caminhos que parecem se estruturar até aqui. De um lado, levando em conta a necessidade de preservação da intimidade dos julgadores e as críticas do filósofo francês Eric Sadin no sentido de que o uso irrefletido da inteligência artificial pode conduzir à "emergência

2 Sobre cada um destes aspectos vide NIEVA FENOLL, Jordi. Inteligencia artificial y proceso judicial. Madrid: Marcial Pons, 2018, passim. 


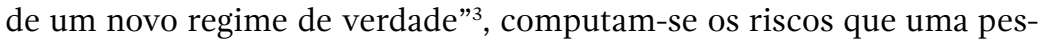
quisa preditiva possa gerar caso não se leve em conta que as máquinas são alimentadas por seres humanos e, nessa medida, os resultados das pesquisas podem advir de preconceitos. De outro, a necessidade de ampliar quadros de compreensão de como operam os processos decisórios das Cortes de Justiça, reforçando a ideia de publicidade das decisões e respectivo "accountability", incorpora-se à abordagem defendida pelos matemáticos Cristian Calude e Giuseppe Longo ao ponderarem o quanto os algoritmos podem auxiliar na promoção de uma melhor prestação jurisdicional ${ }^{4}$. Mais alinhados a essa segunda corrente, os norte-americanos, por exemplo, vêm utilizando a inteligência artificial como ferramenta para predizer processos decisórios já há algum tempo, fazendo-o com certa dificuldade, porém, com relativo sucesso, sem que isso tenha gerado a necessidade de regulamentação legal. Em sentido oposto, os franceses recentemente editaram uma lei tipificando como crime quem resolver coletar dados para esse tipo de análise.

Os radicalismos em geral costumam ser equivocados e não é raro que para suprir esse olhar dicotômico acabe surgindo um meio-termo que equilibre aspectos positivos e negativos de ambos os extremos. Esse, inclusive, parece ser o caminho que vem sendo proposto pela Comissão Europeia para a Eficácia de Justiça - CEPEJ. A questão é saber se é possível identificar um percurso ideal a ser trilhado, pois, não obstante a tecnologia ainda não tenha desenvolvido toda sua potencialidade, vem sendo concretamente empregada em diversos países. Entre estas duas posições vigentes, então, qual será o melhor caminho a se seguir? O uso de inteligência artificial na análise preditiva de decisões processuais penais viola ou assegura garantias constitucionais? Entre a privacidade do julgador e o risco de produção de novos "discursos de verdade", de um lado, e a publicidade processual somada à prestação de contas jurisdicional com melhorias para a segurança jurídica, de outro, o que deve prevalecer? Qual o risco de se ter uma construção dos algoritmos a partir de um entimema,

3 SADIN, Eric. Intelligence Artificielle ou l'enjeu du siècle ( $L$ '): Anatomie d'un antihumanisme radical. Paris: L’Echappée, 2018, p. 81.

4 CALUDE, Cristian; LONGO, Giuseppe. The Deluge of Spurious Correlations in Big Data. In: Foundations of Science. Vol. 22, Issue 3, DOI 10.1007/s10699016-9489-4, 2017, pp. 595-612, p. 611. 
ainda mais quando não ficarem preestabelecidas, de forma clara, qual das diferentes correntes dogmáticas do processo penal foi adotada?

Para nortear a discussão em torno dessas questões se vai à fonte criadora da tecnologia, incursionando no modo como ela se estrutura e se organiza. Parte-se, então, da visão de Alan Turing, considerado o pioneiro na criação da inteligência artificial nos anos 1950, na compreensão e na utilização dos algoritmos no ensinamento das máquinas. Leva-se em conta também a divisão consagrada pelo filósofo John Searle entre inteligência forte e fraca, para limitar o campo de utilização da nova tecnologia. Segue-se ampliando o olhar para os fundamentos filosóficos aristotélicos em torno do método silogístico que embasa o ensinamento da máquina para alcançar o conhecimento, procurando estabelecer os limites e perigos que se tem pela frente.

Por fim, se ingressa na discussão entre os dois modelos de utilização da inteligência artificial preditiva das decisões dos magistrados no âmbito processual penal, analisando, igualmente, o percurso que vem sendo empregado pela Comissão Europeia para a Eficácia de Justiça CEPEJ para estabelecer os melhores fundamentos que possam auxiliar uma eventual tomada de posição a esse respeito no Brasil.

\section{O "JOGO dA IMITAÇÃO" E A DiVISÃo dA INTELIGÊNCIA ARTIFICIAL eM "fracA" E "FORTE".}

Ainda que o espaço e o escopo, aqui, não permitam aprofundar teorias computacionais, para estabelecer as possibilidades de uso democrático da inteligência artificial na predição de decisões no processo penal é preciso ter presente como ela opera.

Ao formular sua ideia original em torno do que depois se denominou de "inteligência artificial”", Alan Turing propôs ilustrá-la através

5 A expressão “inteligência artificial” é atribuída a John McCarthy que, em 1955, a definiu como a ciência de "fazer com que uma máquina tenha um comportamento tal que ele seria chamado de inteligente caso fosse realizado por um ser humano". Conforme MCCARTHY, John; MINSKY, Marvin L.; ROCHESTER, Nathaniel; SHANNON, Claude. A Proposal for the Dartmouth Summer Research Project on Artificial Intelligence, agosto de 1955, p. 11. Vide, também, MCCARTHY, John. Ascribing Mental Qualities to Machines, In: 
do paralelo com o chamado "jogo da imitação", no qual um terceiro dialogando com duas outras pessoas escondidas, procura adivinhar, pelas perguntas e respostas, qual delas seria homem e qual seria mulher 6 . O exemplo do jogo foi tão didático que essa referência passou a ser conhecida pelo "teste de Turing", e vem sendo utilizado para avaliar a capacidade de um programa ou de uma máquina de apresentar comportamento inteligente. Ou seja: o teste mensura se e em quantas possíveis leituras da realidade a máquina é capaz de detectar, compreender, reagir e decidir em comparação a um ser humano e, até mesmo, se ela é capaz de enganar um ser humano, passando-se por outro.

Philosophical perspectives in artificial intelligence, RINGL, M (ed.), Atlantic Highlands, N.J.: Humanities Press, 1979, p. 02.

6 TURING, Alan M.. Computing Machinery and Intelligence, In: Mind, A Quarterly Review of Psychology and Philosophy, New Series, New York: Oxford University Press, vol. LIX, no 236, outubro de 1950, pp. 433-460, p. 433-434. Nas palavras do próprio Turing, em tradução livre: "A nova forma do problema pode ser descrita nos termos de um jogo que denominamos de "jogo da imitação". Ele é jogado com três pessoas: um homem (A), uma mulher (B), e um interrogador $(\mathrm{C})$ que pode ser de qualquer sexo. $\mathrm{O}$ interrogador fica numa sala separada dos outros dois. O objetivo do jogo para o interrogador é determinar qual dos dois outros é o homem e qual é a mulher. Ele os conhece pelos rótulos "X" e "Y" e, ao final do jogo, ele deve dizer "X é A e Y é B" ou "X é B e Y é A". Ao interrogador é autorizado colocar questões para A e B, assim: C: Será que X poderia, por favor, me dizer o comprimento de seu cabelo? Agora imagine que $\mathrm{X}$ realmente seja A, então A deve responder. É tarefa de A no jogo tentar fazer com que C promova uma identificação errônea. Sua resposta, então, pode ser: "Meu cabelo está coberto, e meus fios mais longos são de nove polegadas." Para evitar que o tom da voz auxilie o interrogador as respostas devem ser feitas por escrito, ou melhor ainda, datilografadas. O arranjo ideal é ter uma comunicação via 'teleprinter' entre as duas salas. Alternativamente, as perguntas e respostas podem ser repetidas por um intermediário. O objetivo do jogo para o terceiro jogador (B) é ajudar o interrogador. A melhor estratégia para ela é provavelmente dar respostas verdadeiras. Ela pode dizer coisas como "eu sou a mulher, não dê ouvidos a ele!" em suas respostas, mas isso não vai adiantar nada se o homem puder fazer afirmações semelhantes. Nós, então, formulamos a pergunta: “o que acontecerá quando a máquina tomar o lugar de A nesse jogo?” Será que o interrogador tomará as decisões erradas que tomou quando o jogo for jogado assim, em comparação com as que ele toma quando o jogo é jogado entre um homem e uma mulher?" Estas perguntas substituem nossa pergunta original: “as máquinas podem pensar?" 
O certo, por ora, é que mesmo que uma máquina seja considerada "inteligente", é fundamental compreender qual o alcance dessa inteligência até para saber em quais setores e com qual grau de eficiência ela poderia ser empregada em pesquisas preditivas de decisões dos Tribunais em temas de processo penal.

Desde a divisão criada pelo filósofo John Searle em 1980, consagrou-se na doutrina em geral ${ }^{7}$ a classificação do uso da inteligência artificial em "fraca" e "forte". A inteligência artificial chamada de "fraca", explica Searle, "nos dá ferramentas muito potentes", isto é, "nos permite formular e testar hipóteses de forma mais rigorosa e precisa”, porém, ela depende do inserção de conhecimento fornecido pelo ser humano que a programa, sendo que a máquina não é capaz de produzir raciocínios próprios, autônomos. Já na chamada inteligência artificial "forte", explica Searle, "o computador não é uma mera ferramenta no estudo da mente, ao contrário, o computador adequadamente preparado é realmente uma mente, no sentido de que os computadores que recebem os programas certos poderiam estar, literalmente, preparados para compreender e ter outros estados cognitivos"10. A inteligência "forte", portanto, seria aquela capaz de criar consciência, simulando raciocínios complexos e emitindo opiniões autônomas, independente da interferência constante do ser humano.

A viabilidade da inteligência artificial "forte", no entanto, foi objeto de acirrada crítica por parte de John Searle, valendo-se do exemplo

7 Vide, por todos: RUSSELL, Stuart; NORVIG, Peter. Inteligência Artificial, $3^{\text {a }}$ ed., tradução de Regina Célia Simille, Rio de Janeiro: Campus Elsevier, 2013, p. 1173.

8 SEARLE, John R.. Minds, Brains and Programs, In: The Behavioral and Brain Sciences, 3, Cambridge: Cambridge University Press, 1980, pp. 417457 , p. 417.

9 SEARLE, John R.. Minds, Brains and Programs, In: The Behavioral and Brain Sciences, 3, Cambridge: Cambridge University Press, 1980, pp. 417-457, p. 417. Tradução livre.

10 SEARLE, John R.. Minds, Brains and Programs, In: The Behavioral and Brain Sciences, 3, Cambridge: Cambridge University Press, 1980, pp. 417-457, p. 417. Tradução livre. 
por ele denominado de "o quarto chinês"11, para explicar sua posição. Searle se usa de exemplo imaginando que ele, que não sabe nada da língua chinesa, estaria trancado e isolado num quarto recebendo uma folha de papel na qual estão escritos ideogramas em chinês. Como não conhece a língua, não entende nada do que está escrito. Então, ele recebe uma segunda folha, na qual estão ideogramas chineses acompanhados de um conjunto de regras em inglês que permitem correlacionar a segunda folha com a primeira. E, finalmente, ele recebe uma terceira folha com ideogramas chineses, também com regras em inglês que o orientam a dar em resposta específicos ideogramas chineses vinculados a outros ideogramas da terceira folha, correlacionando os elementos desta terceira folha com as duas anteriores. Pessoas que ele não conhece e estão fora do quarto denominam a terceira folha de "script", a segunda folha de "história" e a primeira folha de "questões". Então, essas pessoas consideram que os símbolos que Searle entregou em resposta à terceira folha são chamados de "respostas às questões" e o conjunto de regras que lhe foi entregue é chamado de "o programa". Searle avança explicando que depois de um tempo ele fica muito bom em dar respostas seguindo as regras que permitem manipular os símbolos chineses e algo similar ocorre com os programadores do lado de fora do quarto, os quais ficam muito bons em escrever os programas de seu ponto de vista externo. Com isso, as respostas que Searle dá às questões se tornam indistinguíveis daquelas que um nativo da língua chinesa daria. Qualquer um que olhe suas respostas não diria que Searle não fala chinês. Sucede que se o mesmo experimento for feito com textos em inglês, língua nativa de Searle, ele daria respostas em patamares similares, igualmente corretas. Com esse experimento, o que Searle quer provar é que, no primeiro caso, em chinês, ele opera como um computador: até responde corretamente, mas não tem a menor ideia do que está respondendo. No segundo, em inglês, ele responde como um ser humano, isto é, sabe perfeitamente o que está respondendo, tem consciência do que responde. Enfim, Searle equipara o quarto ao computador e o ser humano falante de inglês e respondente em chinês ao "software" de inteligência artificial. Para Searle há uma limitação intransponível nessa

11 SEARLE, John R.. Minds, Brains and Programs, In: The Behavioral and Brain Sciences, 3, Cambridge: Cambridge University Press, 1980, pp. 417-457, pp. 417 e ss.. 
conjuntura que impede sua compreensão do que está respondendo em chinês. Partindo desse exemplo, Searle acrescenta uma crítica ainda mais contundente à possibilidade de desenvolvimento da inteligência artificial "forte", dizendo que "a menos que você acredite que a mente é separável do cérebro, tanto conceitual quanto empiricamente - dualismo no sentido forte - você não pode esperar reproduzir a mentalidade escrevendo e rodando programas, já que programas precisam ser independentes do cérebro ou de qualquer outra forma particular de instanciação."

Assim, enquanto o computador responde de forma sintática, a mente humana responde de forma semântica e esta, explica Searle, envolve intencionalidade ${ }^{12}$. É certo que há visão contrária ao pensamento de Searle, sendo a mais incisiva aquela de Daniel Dannett ${ }^{13}$. De outro lado, também é certo que em decorrência do ainda não completo desenvolvimento da inteligência artificial "forte", havendo até mesmo, a partir da crítica de Searle ${ }^{14}$, tanto algum ceticismo em relação à sua potencialidade de efetivação plena ${ }^{15}$, quanto certo conservadorismo fundado no receio de ser ridicularizado e na preocupação em manter a "respeitabilidade" científica ${ }^{16}$, a concentração da análise neste artigo focará na utilização da chamada inteligência artificial "fraca" no processo penal. Esse enfoque também se justifica na medida em que a inteligência artificial "fraca" é

12 SEARLE, John R.. Intencionalidade, tradução de Julio Fischer e Tomás R. Bueno. São Paulo: Martins Fontes, 2002, p. 365.

13 DENNETT, Daniel C.. Darwin's Dangerous Idea: evolution and the meaning of life. New York: Simon \& Schuster Paperbacks, 1995, p. 445.

14 SEARLE, John R.. Minds, Brains and Programs, In: The Behavioral and Brain Sciences, 3, Cambridge: Cambridge University Press, 1980, pp. 417-457pp. 423-424. Tradução livre.

15 Vide, para além do texto original já citado de John Searle, dentre outros: MATHEWS, Eric. Mente: conceitos-chave em filosofia, tradução de Michele Tse, Porto Alegre: Artmed, 2007, pp. 96-97; e também: NILSSON, Nils J. The Quest for Artificial Intelligence: a history of ideas and achievements. New York: Cambridge University Press, 2009, p. 319; PRIMO, Alex; COELHO, Luciano. A chatterbot Cybelle: a experiência pioneira no Brasil, In: RAMOS, Roberto (org.) Mídia, Textos e Contextos. Porto Alegre: Edipucrs, 2001, pp. 259-276, p. 274.

16 BOSTROM, Nick. Superinteligência: caminhos, perigos e estratégias para um mundo novo. Tradução de Aurélio Antonio Monteiro, Clemente Genil Penna, Fabiana Geremias Monteiro, Patricia Ramos Geremias, Rio de Janeiro: Darkside Books, 2018, p. 48. 
justamente aquela que vem sendo usada para estabelecer predições de decisões nos processos e ainda é muito cedo para imaginar programas de inteligência artificial que possam ir além, no sentido "forte" acima referido. Estabelecida esta limitação, antes de ingressar nos problemas de instrução da inteligência artificial "fraca”, é preciso identificar como ela se organiza a partir dos algoritmos.

\section{Algoritmos e dificuldades operacionais da INTELIGÊNCIA ARTIFICIAL.}

Como se vem referindo, não há como estabelecer uma análise crítica das potencialidades de uso da inteligência artificial na predição de decisões dos magistrados no processo penal se não houver mínima compreensão de como ela se estrutura e se organiza. E aqui entram em cena os algoritmos.

São os algoritmos que dão vida à máquina. Eles se caracterizam por um "conjunto de instruções matemáticas" ou "uma sequência de tarefas" que informam "ao computador o que ele deve fazer" "para alcançar um resultado esperado em um tempo limitado" ${ }^{17}$. Para tanto, os computadores requerem "instruções precisas e não ambíguas" ${ }^{18}$. Pedro Domingos ilustra que "os computadores são compostos por bilhões de minúsculas chaves chamadas transistores, e os algoritmos ligam e desligam essas chaves bilhões de vezes por segundo. O algoritmo mais simples é: gire a chave"19.

Então, para que uma máquina possa ser capaz de passar no "teste de Turing”, acima referido, e ser compreendida como dotada de "inteligência artificial”, é preciso dotá-la de tantos algoritmos quantos sejam

17 DOMINGOS, Pedro. O Algoritmo Mestre: como a busca pelo algoritmo de machine learning definitivo recriará nosso mundo, tradução de Aldir José Coelho Corrêa da Silva, São Paulo: Novatec, 2017, p. 24.

18 KAUFMAN, Dora. A Inteligência Artificial irá Suplantar a Inteligência Humana? Barueri, SP: Estação das Letras e Cores, 2018, passim.

19 DOMINGOS, Pedro. O Algoritmo Mestre: como a busca pelo algoritmo de machine learning definitivo recriará nosso mundo, tradução de Aldir José Coelho Corrêa da Silva, São Paulo: Novatec, 2017, p. 24. 
necessários para "ensinar" a máquina, fazendo-a ter a representação do conhecimento e ser capaz de ultrapassar a barreira do idioma natural ${ }^{20}$.

A representação do conhecimento é o ato de descrever um conhecimento, em pedaços, para que a inteligência artificial "assimile" onde e como deverá aplicar tal informação, baseando-se em experiências anteriores. Quando se fala em "conhecimento", portanto, se refere à informação que um "software" precisa para apresentar um comportamento considerado inteligente. Com a aquisição de conhecimento é possível construir o que se denomina de "sistema especialista", isto é, "um programa acoplado a um banco de memória que contém conhecimentos sobre uma determinada especialidade" ${ }^{21}$.

Já a tarefa de vencer a barreira do idioma natural e identificar novas referências linguísticas utilizadas, sejam faladas ou escritas, é mais difícil para a inteligência artificial, pois uma mesma palavra, a depender do contexto, pode ter significados distintos. Para ilustrar a complexidade do que isso representa, aqui calha a lição do "segundo" 22 Wittgenstein ao explicar que quando o ser humano ouve uma palavra, paira-lhe "no espírito a mesma coisa, e que o seu emprego pode ser um outro"23, isto é, pode ter significados diferentes em ocasiões diferentes. Em sentido similar a lição de Warat ao explicar que "a mensagem nunca se esgota na significação de base das palavras empregadas. O sentido gira em torno do dito e do calado. Desta forma, o êxito de uma comunicação depende de como o receptor possa interpretar o sentido latente" ${ }^{24}$. Isso tudo con-

20 DEBESSONET, Cary G.; CROSS, George R. . An Artificial Intelligence Application in the Law: CCLIPS, a Computer Program That Processes Legal Information. In: High Technology Law Journal, Vol. 1, Issue 2, Fall, 1987, pp. 329 e ss.

21 FERNANDES TEIXEIRA, João de. Mentes e Máquinas, Porto Alegre: Artes Médicas, 1998, p. 53.

22 Como é notório, estudiosos de Wittgenstein levam em conta que o filósofo mudou completamente sua forma de compreender a linguagem ao longo da vida e, assim, costumam dividir sua obra em dois momentos distintos, referindo-se ao "primeiro" e ao "segundo" Wittgenstein.

23 WITTGENSTEIN, Ludwig. Investigações Filosóficas. $6^{\mathrm{a}}$ ed., tradução de Marcos G. Nontagnoli, Petrópolis: Vozes, 2009, p. 81.

24 WARAT, Luis Alberto. O Direito e sua Linguagem, $2^{\mathrm{a}}$ ed., Porto Alegre: Sérgio Antonio Fabris Editor, 1995, p. 65. 
duz à conclusão de que nos jogos de linguagem "a palavra deve ter uma família de significados”25.

O que costuma acontecer com a máquina é que ela é "treinada" para ter uma determinada reação frente a tal signo, porém, levando em conta a possibilidade de um significado novo a partir do contexto, resta clara a enorme dificuldade de promover alguns avanços tecnológicos. A ferramenta que tem sido utilizada para a otimização dessa adaptação da máquina com as variações de significados dos signos linguísticos é a interação da inteligência artificial, com simulação de diálogos ${ }^{26}$. Quanto mais os "softwares" possam ser programados para desenvolver habilidade na troca informações com o ser humano em linguagem natural, maior será sua interação ${ }^{27}$.

Isso tudo representa igual desafio quando se trata de alimentar uma inteligência artificial capaz de fazer as predições de decisões de juízes a partir da leitura e interpretação de decisões anteriores.

\section{Paradigmas filosóficos estruturantes do conhecimento.}

Nessa questão toda do ensinamento da máquina parece fundamental compreender que, se é possível ensinar uma máquina a pensar, é porque a estrutura do pensamento é capaz de ser reproduzida e aprendida. E aí é necessário remontar à forma paradigmática pela qual se estrutura o pensamento e o conhecimento humano.

Ao longo da história da humanidade são basicamente três os grandes paradigmas estruturantes do conhecimento: a metafísica clássica aristotélica que está em busca de uma essência e trabalha com a ideia

25 WITTGENSTEIN, Ludwig. Investigações Filosóficas. $6^{\mathrm{a}}$ ed., tradução de Marcos G. Nontagnoli, Petrópolis: Vozes, 2009, p. 57.

26 PRIMO, Alex; COELHO, Luciano Roth. Comunicação e inteligência artificial: interagindo com a robô de conversação Cybelle. In: MOTTA, L. G. M. et al. (Eds.). Estratégias e culturas da comunicação. Brasília: Editora Universidade de Brasília, 2002. p. 83-106.

27 AGRAWAL, Ajay; GANS, Joshua; GOLDFARB, Avi. Máquinas Preditivas: a simples economia da inteligência artificial, tradução de Wendy Campos, Rio de Janeiro: Alta Books, 2018, p. 01. 
de verdade por correspondência ${ }^{28}$; a filosofia da consciência cartesiana, que separa corpo e alma, "fundando" um sujeito solipsista que sozinho diz o mundo a partir de $\mathrm{si}^{29}$; e a filosofia da linguagem, que altera a compreensão de uma relação sujeito-objeto para sujeito-sujeito, usando da linguagem intersubjetivamente construída como condição de possibilidade de compreensão do mundo ${ }^{30}$.

Em que pese sejam formas diferentes de fundamentar a compreensão, todas as três influenciam a humanidade ocidental ainda hoje, operando de forma distinta, de pessoa para pessoa. Assim, é possível dizer que tanto quanto existem pessoas com predominâncias diferentes entre os paradigmas referidos, existem juízes que se comportam em igual disparidade. Portanto, existem juízes que são orientados pela ideia de busca da verdade real e saem atrás das provas que estão no mundo (fundados no paradigma da filosofia aristotélica, de uma verdade por correspondência que não está em mim, mas no mundo); outros que acreditam trazer a verdade dentro de si, desconsiderando as teses e manifestações das partes, e, por vezes, até mesmo a jurisprudência dominante ou a doutrina consagrada, para decidir "de acordo com a sua consciência" (fundados na filosofia da consciência que estrutura um sujeito solipsista, que sozinho diz o mundo a partir de si); e juízes que compreendem a importância da inércia jurisdicional compatibilizada com as garantias do contraditório e da ampla defesa, construindo uma decisão dialogada e intersubjetiva (fundados na intersubjetividade da filosofia da linguagem).

Não obstante os três modelos se apresentem no contexto dos seres humanos, por uma limitação própria das máquinas que ainda estão centradas no modelo da inteligência artificial "fraca", isto é, ainda não possuem "consciência”, sua estruturação se organiza a partir do

28 ARISTÓTELES. Metafisica. $2^{\mathrm{a}}$ ed., tradução de Edson Bini, São Paulo: EDIPRO, 2012, pp. 177-178, 1027b24-1028 2 .

29 DESCARTES, René. O Discurso do Método. In: Descartes: obras escolhidas. Organizadores: J. Guinsburg, Roberto Romano e Newton Cunha. Tradução de J. Guinsburg, Bento Prado Jr., Newton Cunha e Gita K. Guinsburg. São Paulo: Perspectiva, 2010, pp. 75 e 76; 87 e 88.

30 HEIDEGGER, Martin. Ser e Tempo. $2^{a}$ ed., tradução de Márcia Sá Cavalcante Schuback, Petrópolis: Vozes, 2007, pp. 206 e ss. e pp. 209 e ss.. 
paradigma da filosofia clássica aristotélica de busca de uma verdade por correspondência.

Isso tudo compreendido, é possível avançar para refletir em torno dos limites envolvendo a construção dos algoritmos e as influências negativas que o paradigma aristotélico orientado por silogismos possa apresentar.

\section{Algoritmos e os Silogismos aristotélicos.}

Como refere G.L. Simons, é inevitável aos que trabalham na área da inteligência artificial precisar escrutinar a inteligência natural, a fim de identificar "as características-chave, atributos definitivos, etc."31. Trilhando percurso similar, Roberto Vilhena recorda que os algoritmos acabam sendo estruturados nos moldes silogísticos desenhados por Aristóteles ${ }^{32}$. Essa percepção é fácil de assimilar, dado que a humanidade ocidental é primitivamente herdeira dessa estrutura do pensamento lógico e silogístico aristotélico. Também é interessante considerar que, etimologicamente, a palavra silogismo significa "com cálculo", o que denota, desde logo, como esse método é adaptável ao ensinamento da máquina que se vale igualmente de cálculos.

A inteligência artificial, então, utiliza-se de silogismos para imitar a compreensão de algum objeto, ou seja, realiza uma "operação intelectual” que visa alcançar todas as possibilidades de raciocínio. E estes silogismos são construídos através de redes de algoritmos (ou "diagramas de fluxo") introduzidos na máquina. Ao tratar do tema, Jordi Nieva Fenoll ilustra a construção destes diagramas de fluxo com um exemplo básico, porém esclarecedor, de como a máquina é ensinada a encontrar uma solução $0^{33}$ : “Tenho fome. Opção 1: Tenho dinheiro: Subopção A: Compro comida. Subopção B: Poupo e jejuo. Opção 2: Não tenho dinheiro: Subopção

31 SIMONS, G. L.. Introdução à Inteligência Artificial, tradução de Guilherme M. G. Dias Pires, Lisboa: Clássica Editora, 1986, p. 21.

32 VILHENA, Roberto. O seu futuro depende do passado, In: Casa do Saber, 2019, passim.

33 NIEVA FENOLL, Jordi. Inteligencia artificial y proceso judicial. Madrid: Marcial Pons, 2018, p. 21. 
A: Jejuo.Subopção B: Roubo comida." O algoritmo, enfim, retomando a referência de Vilhena, está mais preocupado com a forma do pensamento, com sua estrutura, do que propriamente com o conteúdo. Não que o conteúdo não seja importante, mas, sabendo como o pensamento se estrutura, o algoritmo é capaz de substituir o ser humano. Não à toa, portanto, Simons conclui que "o uso de representações baseadas na lógica tornou-se popular na investigação de inteligência artificial (IA), porque estas ofereciam uma forma simples de derivação de novos factos a partir de factos velhos" ${ }^{34}$.

É interesse compreender isso, pois, se a organização do método silogístico é empregada na inteligência artificial; se ela remete a Aristóteles; e se esse método influencia a humanidade ocidental ainda hoje, é importante compreender como esse pensamento silogístico opera, para ter presente a dimensão de utilização dos algoritmos e saber identificar os riscos que a estrutura silogística conduz. Somente assim se poderão identificar possíveis limitações na estruturação dos programas de inteligência artificial "fraca", visando evitar um uso dissociado da base democrática exigida para o processo penal.

Para tanto, inicia-se ponderando que o silogismo aristotélico pode ser lido em quatro vertentes (silogismo científico, dialético, poético e retórico). De todas essas possibilidades, no entanto, apenas a primeira, denominada pelo próprio Aristóteles de "silogismo científico", serve para a inteligência artificial "fraca", pois utiliza a dedução, a argumentação lógica e, no campo da inteligência artificial, pode ser vista como a análise de algoritmos realizada por "softwares". Esse silogismo científico trabalha com alto grau de previsibilidade, permitindo saber, dada uma determinada configuração algorítmica, qual resultado será alcançado ${ }^{35}$. Nessa linha metodológica muitos autores atribuem o seguinte exemplo de silogismo a Aristóteles: “Todo homem é mortal. Sócrates é um homem. Logo, Sócrates é mortal”36.

34 SIMONS, G. L. Introdução à Inteligência Artificial, tradução de Guilherme M. G. Dias Pires, Lisboa: Clássica Editora, 1986, p. 123.

35 ARISTÓTELES. Analíticos Posteriores. In: Órganon, $2^{\mathrm{a}}$ ed., tradução de Edson Bini, São Paulo: Edipro, 2010, Livro I, §2, 71b18, pp. 253-254.

36 Como refere GUIMARÃES, Rodrigo Régnier Chemim. Atividade Probatória Complementar do Juiz como Ampliação da Efetividade do Contraditório e da 
$\mathrm{Na}$ análise das decisões de juízes, orientada pela construção preditiva, após as reunir em grupo e as catalogar conforme seu teor, a inteligência artificial visa deduzir qual será o futuro entendimento de um juiz ou tribunal em relação a determinada situação. Se essa é a pretensão, e se o uso de silogismos científicos está na base na construção algorítmica, é certo que há uma limitação aqui, até porque a inteligência artificial, mesmo com os dados disponíveis, não poderá chegar sozinha a um entendimento próprio sobre a mesma situação, pois ela ainda não é capaz de produzir uma opinião original. Entra em cena, então, na construção do sistema analítico da máquina, a relação entre dois atores fundamentais: o engenheiro do conhecimento e o perito.

\section{Potencials entimemas na elaboração de sistemas peritos: UM PROBLEMA A SER CONSIDERADO NO EMPREGO DA INTELIGÊNCIA ARTIFICIAL EM ANÁLISES PREDITIVAS.}

Para que se possa desenvolver uma inteligência artificial capaz de ser aplicada ao processo penal com alguma utilidade, será necessário contar com a cooperação entre um engenheiro do conhecimento ${ }^{37}$, isto é, aquele profissional encarregado de promover a programação heurística que instruirá a máquina e a fará “inteligente”, e um perito.

O engenheiro do conhecimento e o perito dialogam na elaboração de um sistema perito capaz de ser empregado para solução de uma determinada questão prática. O engenheiro do conhecimento deve "mergulhar" no universo do perito, promovendo entrevistas e trocando impressões

Ampla Defesa no Novo Processo Penal Brasileiro. Tese, Curitiba: Universidade Federal do Paraná, 2017, p. 35: "No entanto, não há nenhuma passagem na obra de Aristóteles que utilize o referido exemplo e este, então, parece mais uma forma consagrada pela tradição de exemplificar o silogismo aristotélico. Jan Lukasiewicz informa que uma variação desse famoso exemplo, com referência a "animal" ao invés de "mortal", encontra-se em texto de Sexto Empírico (160 a. C.). Aristóteles, por sua vez, dá exemplos menos "poéticos": "Se A se aplica a B, e B a C, A se aplica a C"; ou, então: "Pitaco é liberal, porque aqueles que prezam a honra são liberais e Pitaco preza a honra"”

37 FERNÁNDEZ, Gregorio. Panoramas de los sistemas expertos. In: CUENA, José (org.) Inteligencia Artificial: sistemas expertos. Madrid: Alianza Editorial, 1986, pp. 23-52, p. 38. 
com o intuito de reduzir a complexidade do campo específico do conhecimento às questões centrais que são necessárias para a máquina realizar determinada tarefa. Ele deve, enfim, "persuadir o perito a traduzir a sua perícia numa forma que possa ser armazenada numa base de dados" 38 . E aqui se estabelecem alguns perigos quando se pensa em programação voltada para o processo penal.

O primeiro perigo reside tanto na incapacidade do perito escolhido para servir de ponte com o conhecimento específico do processo penal, quanto na incapacidade de tradução dos aspectos relevantes do direito e do processo penal pelo engenheiro do conhecimento. Não é preciso muito esforço para identificar na doutrina de processo penal de hoje em dia uma pluralidade bastante significativa de discursos e fundamentos antagônicos.

Esse tipo de problema não é uma exclusividade do processo penal, por óbvio, sendo mesmo uma preocupação geral quando se trata de elaborar sistemas peritos ${ }^{39}$. No entanto, no processo penal ele é significativamente marcante, dada a variedade de visões coexistentes na doutrina. Por exemplo: se o perito for um doutrinador mais "tradicional" ele é capaz dele indicar que a função do juiz no processo penal seja a "busca da verdade real". Porém, se for um doutrinador mais "moderno", isto é, que faça leituras transdisciplinares ${ }^{40}$ da complexidade do processo penal e premie leituras e filtragens constitucionais das regras processuais, ele refutará essa ideia como ponto de partida. Aliás, mesmo entre os doutrinadores mais “modernos" há ampla disparidade a respeito de qual seja o papel do juiz nessa questão, indo da inércia absoluta ${ }^{41}$ até

38 SIMONS, G. L. Introdução à Inteligência Artificial, tradução de Guilherme M. G. Dias Pires, Lisboa: Clássica Editora, 1986, p. 112.

39 FERNÁNDEZ, Gregorio. Panoramas de los sistemas expertos. In: CUENA, José (org.) Inteligencia Artificial: sistemas expertos. Madrid: Alianza Editorial, 1986, pp. 23-52, p. 45.

40 Como refere COUTINHO, Jacinto Nelson de Miranda. Dogmática Crítica e Limites Linguísticos da Lei. In: Diálogos Constitucionais: direito, neoliberalismo e desenvolvimento em países periféricos. COUTINHO, Jacinto Nelson de Miranda; LIMA, Martonio Mont'Alverne Barreto (Organizadores). Rio de Janeiro: Renovar, 2006, pp. 225-232, p. 227.

41 V.g. KHALED JR., Salah H. A busca da verdade no processo penal: para além da ambição inquisitorial. São Paulo: Atlas, 2013, p. 151; BARROS, Flaviane 
a compatibilização com posturas ativas na produção da prova ${ }^{42}$. Essa mesma disparidade doutrinária se reproduz no comportamento e na exegese dos juízes criminais. Ao se conduzir uma pesquisa em torno do modo decisório dos juízes e dos tribunais, portanto, seria importante, no mínimo, deixar clara a opção que embasa a construção do sistema perito e que alimentará a inteligência artificial.

O segundo perigo decorre da necessidade do engenheiro do conhecimento "decidir qual das várias estruturas de resolução de problemas ("procedimentos de inferência") é a mais adequada para o assunto específico" ${ }^{43}$. Em verdade, esse é um esforço de contínuo aperfeiçoamento que deve nortear a elaboração de qualquer sistema perito. Como recorda G. L. Simons, “os programadores deverão ter por objectivo produzir o primeiro esboço do sistema tão rapidamente quanto possível, se não por outra razão, para conservar o interesse do perito”. E complementa dizendo que "é provável que ocorram erros na primeira versão, e o envolvimento do perito será essencial para que ela seja melhorada. É nessa altura que as inconsistências nos conhecimentos do perito, ou a sua compreensão superficial dos seus vários métodos de resolução efectiva de problemas, são provavelmente expostas" ${ }^{44}$.

Retoma-se aqui o problema do emprego de algoritmos na elaboração de uma inteligência artificial. Se ele parte de um silogismo científico,

de Magalhães. (Re)forma do Processo Penal: comentários críticos dos artigos modificados pelas leis n. 11.690/08 e 11.719/08. Belo Horizonte: Del Rey, 2009, pp. 50-51; TASSE, Adel El; MILÉO, Eduardo Zanoncini; PIASECKI, Patrícia Regina. O Novo Sistema de Provas no Processo Penal. Comentários à Lei 11.690/08. Curitiba: Juruá, 2008, p. 65.

42 Admitindo, por exemplo, que o juiz possa ao menos complementar a inquirição das testemunhas nos moldes hoje permitidos pelo art. 212 do Código de Processo Penal: v.g. COUTINHO, Jacinto Nelson de Miranda. Sistema Acusatório e Outras Questões Sobre a Reforma Global do CPP. In: COUTINHO, Jacinto Nelson de Miranda e CARVALHO, Luis Gustavo Grandinetti Castanho (Organizadores) O Novo Processo Penal à Luz da Constituição. Volume 2. Rio de Janeiro: Lumen Iuris, 2011, pp. 20-21; LOPES JR., Aury. Direito Processual Penal. $10^{\mathrm{a}}$ ed., São Paulo: Saraiva, 2013, p. 657.

43 SIMONS, G. L. Introdução à Inteligência Artificial, tradução de Guilherme M. G. Dias Pires, Lisboa: Clássica Editora, 1986, p. 113. 
como acima destacado, pode ocorrer algo equivalente ao problema que o próprio Aristóteles alertava para a adequada elaboração de um silogismo: não atentar para a necessidade de que a premissa maior seja verdadeira. Aqui se corre o risco de um engenheiro do conhecimento ou um programador ensinarem a máquina de forma errada, isto é, partindo de um entimema. Como explica Aristóteles, o "entimema [é] formado de poucas premissas e em geral menos do que o silogismo primário", "porque se alguma dessas premissas for bem conhecida, nem sequer é necessário enunciá-la; pois o próprio ouvinte a supre". ${ }^{45}$

Se o entimema é formado uma premissa maior dada como cer$\mathrm{ta}^{46}$, é preciso entender que esta, por sua vez, pode estar se originando de um preconceito, o qual pode ser até mesmo indemonstrável, quiçá originário do inconsciente, e pode estar presente, seja no perito por ocasião da orientação ao engenheiro que ensinará a máquina, seja no juiz cujas decisões anteriores serão analisadas pela inteligência artificial para elaborar a predição.

É, portanto, na interseção entre a filosofia e a psicanálise, e na presença do silogismo que embasa a inteligência artificial que a construção do entimema e a análise preditiva ganham complexidade. Tudo isso casa com a preocupação do filósofo francês Eric Sadin, destacada no documento da Comissão Europeia para a Eficácia da Justiça, de dizer que a ideia de "neutralidade" dos algoritmos é um mito ${ }^{47}$. Talvez isso tudo explique os dois caminhos que vêm sendo trilhados quanto à possibilidade de se admitir o uso da inteligência artificial na elaboração de predições das decisões judiciais e sirva de alerta para que se tenha maior

45 ARISTÓTELES. Retórica. Tradução de Edson Bini, São Paulo: Edipro, 2011, I, 1357a.

46 Como detalha ADEODATO, João Maurício. Ética e Retórica: para uma teoria da dogmática jurídica, $5^{\text {a }}$ ed., São Paulo: Saraiva, 2012, p. 302: “Aristóteles junta os topoi que servem para fundamentar os entimemas, sejam reais ou aparentes: o emprego de oposições e equivalências de termos (antônimos e sinônimos), a comparação, diferenças de grau, experiências anteriores, polissemias, ambiguidades, juízos de valor generalizados. Ele enumera vinte e oito desses pontos de vista, fornecendo exemplos de topoi construindo entimemas."

47 EUROPA. Conselho da Europa. Comissão Europeia para a Eficácia da Justiça, Carta Ética Europeia de Utilização da Inteligência Artificial nos Sistemas Judiciários e seu Entorno, Estrasburgo: CEPEJ, 03 de dezembro de 2018, p. 61. 
cuidado na construção dos sistemas peritos que nortearão as pesquisas preditivas daqui em diante.

\section{O MODELO DE PESQUISA NORTE-AMERICANO.}

Em 2017 os pesquisadores norte-americanos Daniel Martin Katz, Michael J. Bommarito e Josh Blockman fizeram um experimento com a Suprema Corte daquele país utilizando um "software" capaz de prever votos em processos. Realizaram uma análise dos julgados de dois séculos daquela Corte, acertando 70,2\% dos resultados dos julgados e 71,9\% dos votos dos juízes ${ }^{48}$. Estabeleceram a possibilidade de decisões serem previstas por inteligência artificial, utilizando os parâmetros dos próprios juízes. Levaram em conta três outras pesquisas anteriores (realizadas entre 2004 e 2011), que haviam alcançado resultados limitados e questionáveis, decorrência do quanto de dados eram inseridos no sistema ${ }^{49}$. Nas pesquisas anteriores a análise era limitada à composição plena da Suprema Corte e se circunscrevia ao momento anterior à mudança de algum de seus integrantes. A última pesquisa teve a pretensão de utilizar a inteligência artificial que fosse capaz de manter as previsões, mesmo com a alteração de magistrados ao longo dos anos.

Como insumos para alimentar a inteligência artificial os pesquisadores utilizaram o Banco de Dados da Suprema Corte (SCDB) e "alguns recursos derivados da engenharia de recursos" ${ }^{50}$, não deixando claro quais seriam estes últimos.

48 KATZ, Daniel Martin; BOMMARITO, Michael J.; BLOCKMAN, Josh. A general approach for predicting the behavior of the Supreme Court of the United States, In: PLoS ONE, 12(4): e0174698, 2017, passim.

49 MARTIN, A. D.; QUINN, K.M.; RUGER, T.W.; KIM, P.T.. Competing approaches to predicting supreme court decision making, In: Perspectives on Politics, 2004; 2(4), pp. 761-767; e também GUIMERÀ, R., SALES-PARDO, M.. Justice blocks and predictability of us supreme court votes. In: PloS One, 2011; 6(11):e27188. pmid:22096533; e, ainda, RUGER, T. W.; KIM, P. T.; MARTIN, A. D.; QUINN, K. M.. The supreme court forecasting project: Legal and political science approaches to predicting supreme court decisionmaking, In: Columbia Law Review, New York: Columbia Law School, 2004; 104(4), pp. 1150-1209.

KATZ, Daniel Martin; BOMMARITO, Michael J.; BLOCKMAN, Josh. A general approach for predicting the behavior of the Supreme Court of the United 
Quanto ao que inferiram do banco de dados referido os pesquisadores relataram algumas dificuldades interessantes. Disseram que uma delas residiu, por exemplo, no fato de que a Suprema Corte norte-americana por vezes julga pressionada pela opinião pública, ou influenciada pelo conflito entre agências estatais, a ponto de invocarem uma máxima por lá consagrada: “desempenho passado não necessariamente prediz resultados futuros".

Relataram, também, dificuldades em compatibilizar a pesquisa com a mudança jurisprudencial repentina, que esvazia as referências anteriores na predição futura. Seguiram aduzindo que outra dificuldade se relaciona com o fato de que em cada decisão encontraram "até duzentos e quarenta variáveis, incluindo variáveis cronológicas, variáveis de fundo de caso, variáveis específicas de Justiça e variáveis de resultado. Muitas dessas variáveis são categóricas, assumindo centenas de valores possíveis. Por exemplo, a variável de problema pode ter 384 valores distintos”.

Tentaram, então, estabelecer alguns parâmetros padronizados para a pesquisa, criando um mapa de codificação que definia uma coluna para os votos singulares e outra para a decisão final do colegiado. Os votos e a decisão da Corte eram catalogados como "reversos" (quando eram pela mudança da decisão da Corte inferior); "afirmativos" (quando se decidiam por manter a decisão recorrida) e "outros" (quando a decisão caminhava para uma solução diversa, por exemplo, perda de objeto).

Depois relacionaram as referências utilizadas no SCDB: qual ministro, qual o mandato do ministro, juiz natural, mês de discussão, requerente, requerido, competência originária ou recursal, ações administrativas, tribunal de origem, fonte do caso, desacordo de primeira instância, motivo para decidir pela análise do caso na Suprema Corte, decisão da primeira instância, composição do tribunal de origem e qual era o tema.

Acrescentaram variáveis dos tribunais inferiores identificando que, a depender do tribunal de origem, a decisão da Suprema Corte era tendente a ser num sentido. Em seguida adicionaram novos dados: se houve ou não sustentação oral; se houve mais de uma sessão de julgamento; o tempo de discussão do caso. O tempo, perceberam os pesquisadores, influencia na decisão ser unânime ou não.

States, In: PLoS ONE, 12(4): e0174698, 2017, passim. 
Por fim, desenvolveram recursos que resumiam o "comportamento" de um juiz ou tribunal de primeira instância e a diferença entre eles, dividindo essas características em três categorias: (1) características relacionadas à taxa de reversão; (2) características relacionadas à orientação política da decisão, se de esquerda ou de direita; e (3) características relacionadas à taxa de dissidência. Incluíram, ainda, um termo de diferença entre a decisão de primeira instância e decisão média historicamente observada, o que permitiu identificar o quão distante, ideologicamente, estava a opinião do juiz de primeira instância em comparação com o ministro da Suprema Corte, revelando tendências políticas e processuais dos Tribunais e dos juízes.

Os pesquisadores ainda indicaram que se utilizaram do chamado "algoritmo da floresta aleatória" ("random forest"). Este algoritmo é de aprendizagem supervisionada e cria combinações de árvores de decisão $0^{51}$.

Este modelo norte-americano de pesquisa livre, predominante naquele país, então, como se vê da explicação da última experiência realizada, é bastante complexo e necessitou da contribuição das referidas pesquisas anteriores para identificar e corrigir algumas falhas. A tendência é que com o tempo novas pesquisas avancem ainda mais. Não há notícia de reação negativa institucional por parte da Suprema Corte daquele país, nem tampouco que o Congresso norte-americano esteja pensando em regrar a análise preditiva de julgados, o que indica que não há regulamentação cerceadora da atividade de pesquisa empírica que possa predizer o modo de julgar dos tribunais norte-americanos.

51 Niklas Donges apresenta uma analogia facilitadora para compreender o algoritmo da floresta aleatória: "Andrew quer decidir para onde viajar em suas férias de um ano, então ele pede sugestões para as pessoas que mais bem o conhecem. O primeiro amigo que ele encontra lhe pergunta a respeito do que ele gostou e do que não gostou em suas viagens anteriores. Baseado nestas respostas, ele dá algumas sugestões a Andrew. Esta é uma abordagem típica de árvores de decisão. $\mathrm{O}$ amigo de Andrew criou regras para guiar sua decisão sobre o que deveria recomendar, usando para tanto as respostas de Andrew. Depois disto, Andrew começa a pedir conselhos para mais e mais amigos e eles novamente fazem diferentes perguntas das quais eles conseguem extrair algumas recomendações. Finalmente, Andrew escolhe os lugares que receberam mais recomendações, o que é uma abordagem típica de florestas aleatórias." (DONGES, Niklas. A Complete Guide to the Random Forest Algorithm. In: Built In, 16 de junho de 2019). 


\section{A Reação fRANCESA.}

Na França a situação é totalmente oposta àquela norte-americana. O Poder Legislativo francês aprovou, no dia 23 de março de 2019, a Lei 2019-222, alterando o artigo L10 do Código de Justiça Administrativa francês para alcançar o extremo de criminalizar a conduta de quem "divulga os dados de identidade dos magistrados e membros do registro" que "não podem ser objeto de reutilização com a finalidade ou efeito de avaliar, analisar, comparar ou prever suas práticas profissionais reais ou alegadas" ${ }^{2}$, punida com uma pena máxima de 5 (cinco) anos.

O mais curioso é que a lei foi precedida de uma decisão do Conselho Constitucional francês ("Conseil constitutionnel") ${ }^{53}$, que é um colegiado de nove membros com jurisdição para analisar a constitucionalidade das leis, inclusive "ex ante", como neste caso. Na análise do caso, o Conselho Constitucional francês refere aos argumentos de alguns deputados que levaram o caso até ele, os quais contestavam a regra que impunha o sigilo e a proibição de conhecimento dos nomes dos juízes e da sua jurisprudência, aduzindo que o conhecimento destes favoreceria a igualdade entre os litigantes. As críticas também foram feitas por outros deputados e senadores, ao argumento central de ferimento do princípio da publicidade.

O Conselho, por sua vez, ponderou que "o legislador pretendia evitar que a reutilização dos nomes e decisões dos juízes permitisse, por meio de processamento de dados pessoais, traçar o perfil dos profissionais da área jurídica com base nas decisões tomadas, o que poderia levar à pressão ou escolha de estratégias de jurisdição ou alterar o funcionamento da Justiça" ${ }^{54}$. E seguiu ponderando que "estas disposições não criam, portanto, qualquer disfunção injustificada entre litigantes e não infringem o direito a um procedimento justo e equitativo que garanta o equilíbrio dos direitos das partes" ${ }^{55}$. E, assim, concluíram pela constitucionalidade

52 FRANÇA. Lei 2019-222, de 23 de março de 219. Artigo 33.

53 FRANÇA. Conseil Constitucionnel. Décision $n^{o}$ 2019-778 DC du 21 mars 2019.

54 FRANÇA. Conseil Constitucionnel. Décision $n^{o}$ 2019-778 DC du 21 mars 2019, parágrafo 93. Tradução livre.

55 FRANÇA. Conseil Constitucionnel. Décision $n^{o}$ 2019-778 DC du 21 mars 2019, parágrafo 94. Tradução livre. 
da criação do tipo penal referido, dando carta branca ao Parlamento para seguir na edição da referida lei.

Ao criminalizar pesquisas sobre os julgados, o novo regramento francês indica caminhar no sentido oposto à tradição iluminista de considerar a publicidade como garantia, insculpida, a partir da Revolução Francesa, inclusive e em certa medida, até mesmo na Declaração Universal dos Direitos do Homem e do Cidadão, de 1789. Com efeito, ainda que o Conselho francês tenha afirmado em sentido inverso, fixando sua análise nos artigos $6^{\circ}$ e 16 da Declaração, olvidou do artigo 15 do mesmo histórico diploma normativo. Este estabelece que "a sociedade tem o direito de pedir contas a todo agente público pela sua administração", de onde decorre o dever de "accountability", isto é, de prestação de contas, e, por conseguinte, de publicidade dos atos do poder público, aqui incluindo, por evidente, as decisões dos juízes.

\section{O ponto de equilíbrio da Comissão Europeia para a Eficácia DA Justiça - CEPEJ: ENTRE A FILOSOFIA CRÍtICA DE ERIC SADIN E o otimismo matemático de Cristian Calude e Giuseppe Longo.}

Os dois extremos evidenciados entre o que se produz nos Estados Unidos e a proibição criminalizadora da legislação francesa parecem escapar do quanto vem sendo trabalhado no âmbito da comunidade europeia em torno do tema da tecnologia da informação e comunicação dos sistemas europeus de Justiça.

Em sua $31^{\text {a }}$ reunião plenária realizada nos dias 03 e 04 de novembro de 2018, a Comissão Europeia para a Eficácia da Justiça ("Commission européenne pour l'efficacité de la justice - CEPEJ”) editou uma "Carta Ética Europeia de Utilização da Inteligência Artificial nos Sistemas Judiciários e seu Entorno" ${ }^{56}$. Nela se evidencia certo receio da Comissão Europeia quanto ao uso da inteligência artificial, mas a Carta Ética está longe de proibir o emprego da tecnologia e, mesmo muito distante da iniciativa francesa de tipificar pesquisas preditivas de jurisprudência como crime.

56 EUROPA. Conselho da Europa. Comissão Europeia para a Eficácia da Justiça. Carta Ética Europeia de Utilização da Inteligência Artificial nos Sistemas Judiciários e seu Entorno, Estrasburgo: CEPEJ, 03 de dezembro de 2018. 
A Comissão Europeia faz, no entanto, algumas ressalvas, dizendo que "o termo "justiça preditiva" deve ser refutado porque é ambíguo e falacioso" e que "os vieses de análise, se eles não podem ser totalmente excluídos, devem ser identificados" ${ }^{\prime 7}$. Seja como for, em geral, ainda que a Carta Europeia externe certa preocupação, ela não proíbe, de partida, a análise de decisões judiciais e a estruturação de mecanismos de inteligência artificial que possam ser preditivos.

Aliás, na $32^{\mathrm{a}}$ e última reunião plenária realizada pela Comissão Europeia para a Eficácia da Justiça, em 14 de junho de 2019 (posterior à edição da lei francesa, portanto), elaborou-se um documento denominado "Caixa de ferramentas para apoiar a implantação das Diretrizes na condução da mudança para a ciberjustiça”, no qual se registram recomendações no sentido de facilitar a supervisão dos tribunais e do Ministério Público, bem como garantir a transparência, inclusive no sentido de combater a corrupção e oferecer um "sistema razoavelmente previsível"58.

Nesse campo, portanto, a lei francesa caminha contra a tendência externada nas reuniões plenárias e nas diretrizes europeias recomendadas pela Comissão Europeia para a Eficácia da Justiça, do Conselho da Europa. Enquanto na Comissão Europeia não há vedação para as pesquisas preditivas, na França a conduta é criminalizada.

Uma das maiores preocupações da Comissão Europeia, no entanto, vem na trilha do alerta de Eric Sadin ao dizer que a ideia de "neutralidade" dos algoritmos é um mito ${ }^{59}$. Aqui transparece um ponto de inflexão entre o modelo liberal norte-americano e o modelo proibicionista francês. Essa preocupação de Eric Sadin se revela importante, notadamente quando se toma como séria a possibilidade da instrução da máquina de inteligência artificial ser organizada a partir de possíveis entimemas que possam ser

57 EUROPA. Conselho da Europa. Comissão Europeia para a Eficácia da Justiça. Carta Ética Europeia de Utilização da Inteligência Artificial nos Sistemas Judiciários e seu Entorno, Estrasburgo: CEPEJ, 03 de dezembro de 2018, p. 61.

58 EUROPA. Conselho da Europa. Comissão Europeia para a Eficácia da Justiça, Boîte à outils pour soutenir la mise en œuvre des Lignes Directrices sur la conduite du changement vers la cyberjustice, Estrasburgo: CEPEJ, 13-14 de junho de 2019, pp. 14-15.

59 EUROPA. Conselho da Europa. Comissão Europeia para a Eficácia da Justiça, Carta Ética Europeia de Utilização da Inteligência Artificial nos Sistemas Judiciários e seu Entorno, Estrasburgo: CEPEJ, 03 de dezembro de 2018, p. 61. 
o norte da pesquisa ou mesmo na dificuldade de conduzir uma pesquisa quando há ampla disparidade entre as bases teóricas em processo penal. Eric Sadin ainda alerta que o uso irrefletido da inteligência artificial pode conduzir à "emergência de um novo regime de verdade" ${ }^{60}$. No entanto, isso não parece suficientemente potente para a Comissão Europeia abrir mão do acesso pleno do quanto decidem os juízes e tribunais em processos penais. A publicidade aqui, fala mais alto e, mesmo que existam riscos nas pesquisas preditivas caso não se leve em conta que as máquinas são alimentadas por seres humanos e, nessa medida, os resultados das pesquisas podem advir de preconceitos, tendo isso como presente se aposta na possibilidade de construir sistemas peritos capazes de minimizar esses riscos. A ideia de dar preferência à publicidade das decisões e respectivo "accountability" acaba sendo defendida pelo embasamento conclusivo dos matemáticos Cristian Calude e Giuseppe Longo ao ponderarem que "nossos limitados ou "negativos" resultados, como ocorrem frequentemente (Longo 2008), não "destroem" a ciência de dados, mas abrem caminho para mais reflexões” ${ }^{61}$, ou seja, no que concerne à Comissão Europeia, não é possível abandonar o quanto os algoritmos podem auxiliar na análise preditiva dos julgados e, assim, promoção de uma melhor prestação jurisdicional.

Quanto à possibilidade de as estatísticas gerarem compreensões equivocadas ou mesmo substituir a ciência, Cristian Calude e Giuseppe Longo ponderam que "na mesma medida que a análise de big data não pode substituir a ciência, nenhuma teoria pode ser tão boa para abandonar a necessidade de dados e testes" ${ }^{2}$. O ponto de equilíbrio, portanto, parece ser o melhor caminho encontrado pela Comissão Europeia nesses primeiros passos das pesquisas preditivas de jurisprudência no âmbito processual penal.

60 SADIN, Eric. Intelligence Artificielle ou l'enjeu du siècle (L'): Anatomie d'un antihumanisme radical. Paris: L'Echappée, 2018, p. 81.

61 CALUDE, Cristian; LONGO, Giuseppe. The Deluge of Spurious Correlations in Big Data. In: Foundations of Science. Vol. 22, Issue 3, pp. 595-612, DOI 10.1007/s10699-016-9489-4, 2017, p. 611..

62 CALUDE, Cristian; LONGO, Giuseppe. The Deluge of Spurious Correlations in Big Data. In: Foundations of Science, Vol. 22, Issue 3, DOI 10.1007/s10699016-9489-4, 2017, pp. 595-612, p. 611.. 


\section{CONSIDERAÇÕES FINAIS}

Analisadas e compreendidas as questões técnicas que envolvem a adoção da inteligência artificial "fraca", é possível chegar a algumas conclusões a respeito dos questionamentos formulados na introdução e de como deve se dar o uso dessa ferramenta tecnológica na elaboração de pesquisas preditivas.

De partida é importante considerar os riscos de relacionamento entre o engenheiro do conhecimento e um perito em processo penal. Isso se dá não apenas pela difícil tradução de alguns temas de processo para uma linguagem algorítmica, mas pela ampla gama de diferentes visões de processo penal que hoje ainda coexistem e pela possibilidade de que as construções algorítmicas partam de entimemas. No mínimo, neste ponto, é preciso deixar claras as opções teóricas de processo penal para não confundir os intérpretes dos resultados que sejam produzidos nas pesquisas. Os vieses de análises, portanto, devem ser identificados, tornados claros e transparentes.

Tendo essas premissas em mente, as posturas antagônicas que vêm sendo adotadas pelos Estados Unidos e pela França, isoladamente vistas, não se apresentam como soluções adequadas. A criminalização de pesquisas preditivas promovida na França não é um caminho a ser seguido em termos de controles democráticos, pois aniquila a garantia da publicidade processual. Com efeito, a justificativa francesa pautada na privacidade dos julgadores colide com a publicidade processual e com a necessidade de prestação de contas à sociedade. E esta garantia processual penal deve prevalecer num aparente conflito, pois numa democracia quem exercita o poder tem o dever de prestar contas de seus atos. A publicidade das decisões judiciais diminui a possibilidade de abusos no exercício do poder e, como tal, é uma garantia processual fundamental que se sobrepõe ao interesse de privacidade dos julgadores.

Por outro lado, a preocupação do filósofo Eric Sadin no sentido de que o uso desenfreado da inteligência artificial possa conduzir à dependência dela na tomada de decisões, promovendo uma "emergência de um novo regime de verdade”, não pode ser desconsiderada. E as pesquisas norte-americanas não parecem atentar para esses aspectos. A Comissão Europeia para a Eficácia da Justiça equilibra essa preocupação com a 
invocação das ponderações dos matemáticos Cristian Calude e Giuseppe Longo de que "nenhuma teoria pode ser tão boa para abandonar a necessidade de dados e testes". A forma de neutralizar possível construção de novas verdades absolutas, passa pelo quanto anotado acima, isto é, tornar públicos e claros os vieses de construção dos algoritmos. Assim, esse meio termo sugerido pela Comissão Europeia, entre o radicalismo francês e a ausência de preocupação dos norte-americanos com a prevalência de "novos regimes de verdade", para seguir emprestando a preocupação de Eric Sadin, pode ser um caminho a ser também trilhado no Brasil, até porque, por aqui, já estão aparecendo pesquisas similares ${ }^{63}$.

Portanto, evitar que os critérios de alimentação dos programas possam conduzir a resultados equivocados e estes, por sua vez, possam influenciar negativamente novas tomadas de decisão dos tribunais, ou, até mesmo, induzir a necessidade de reformas legislativas que diminuam direitos e garantias, deve nortear as pesquisas preditivas.

Muito ainda há para ser esclarecido, compreendido, empregado e delimitado no uso dessa nova tecnologia para fins preditivos, mas entre seguir um caminho de livre exploração, como parece indicar o percurso norte-americano, ou adotar uma solução radical inversa de criminalização da conduta, como está conduzindo a França nesse momento, a primeira opção, acrescida de uma dosagem maior de cautela nos moldes do quanto já documentado pela Comissão Europeia para a Eficácia da Justiça, parece ser o ponto de partida, devendo ser mantidas novas pretensões investigativas.

\section{REFERÊNCIAS}

ADEODATO, João Maurício. Ética e Retórica: para uma teoria da dogmática jurídica, $5^{a}$ ed., São Paulo: Saraiva, 2012.

AGRAWAL, Ajay; GANS, Joshua; GOLDFARB, Avi. Máquinas Preditivas: a simples economia da inteligência artificial, tradução de Wendy Campos, Rio de Janeiro: Alta Books, 2018.

${ }^{63}$ LAGE-FREITAS, André; ALLENDE-CID, Héctor; SANTANA, Orivaldo; OLIVEIRA-LAGE, Lívia de. Predicting Brazilian court decisions. In: arXiv.org. Ithaca: Cornell University, 1905.10348v1 [cs.SI], 20 de abril de 2019. 
ARISTÓTELES. Metafisica. $2^{\mathrm{a}}$ ed., tradução de Edson Bini, São Paulo: EDIPRO, 2012.

ARISTÓTELES. Analíticos Posteriores. In: Órganon, $2^{\mathrm{a}}$ ed., tradução de Edson Bini, São Paulo: Edipro, 2010.

ARISTÓTELES. Retórica, tradução de Edson Bini, São Paulo: Edipro, 2011.

BARROS, Flaviane de Magalhães. (Re)forma do Processo Penal: comentários críticos dos artigos modificados pelas leis n. 11.690/08 e 11.719/08. Belo Horizonte: Del Rey, 2009.

BOSTROM, Nick. Superinteligência: caminhos, perigos e estratégias para um mundo novo, tradução de Aurélio Antonio Monteiro, Clemente Genil Penna, Fabiana Geremias Monteiro, Patricia Ramos Geremias, Rio de Janeiro: Darkside Books, 2018.

CALUDE, Cristian; LONGO, Giuseppe. The Deluge of Spurious Correlations in Big Data. In: Foundations of Science, vol. 22, Issue 3, DOI 10.1007/s10699-0169489-4, 2017, pp. 595-612, p. 611, disponível em https://www.di.ens.fr/users/ longo/files/BigData-Calude-LongoAug21.pdf, acesso em 08 de setembro de 2019.

COUTINHO, Jacinto Nelson de Miranda. Dogmática Crítica e Limites Linguísticos da Lei. In: Diálogos Constitucionais: direito, neoliberalismo e desenvolvimento em países periféricos. COUTINHO, Jacinto Nelson de Miranda; LIMA, Martonio Mont'Alverne Barreto (Organizadores). Rio de Janeiro: Renovar, 2006, pp. 225-232.

COUTINHO, Jacinto Nelson de Miranda. Sistema Acusatório e Outras Questões Sobre a Reforma Global do CPP. In: COUTINHO, Jacinto Nelson de Miranda e CARVALHO, Luis Gustavo Grandinetti Castanho (Organizadores) O Novo Processo Penal à Luz da Constituição. (Análise Crítica do Projeto de Lei n. 156/2009, do Senado Federal). Volume 2, Rio de Janeiro: Lumen Iuris, 2011.

DEBESSONET, Cary G.; CROSS, George R. . An Artificial Intelligence Application in the Law: CCLIPS, a Computer Program That Processes Legal Information. In: High Technology Law Journal, Vol. 1, Issue 2, Fall, 1987.

DENNETT, Daniel C.. Darwin's Dangerous Idea: evolution and the meaning of life. New York: Simon \& Schuster Paperbacks, 1995.

DESCARTES, René. O Discurso do Método. In: Descartes: obras escolhidas. Organizadores: J. Guinsburg, Roberto Romano e Newton Cunha. Tradução de J. Guinsburg, Bento Prado Jr., Newton Cunha e Gita K. Guinsburg. São Paulo: Perspectiva, 2010.

DOMINGOS, Pedro. O Algoritmo Mestre: como a busca pelo algoritmo de machine learning definitivo recriará nosso mundo, tradução de Aldir José Coelho Corrêa da Silva, São Paulo: Novatec, 2017. 
DONGES, Niklas. A Complete Guide to the Random Forest Algorithm. In: Built In, 16 de junho de 2019. https://builtin.com/data-science/random-forest-algorithm, acesso em 02 de setembro de 2019.

EUROPA. Conselho da Europa. Comissão Europeia para a Eficácia da Justiça. Carta Ética Europeia de Utilização da Inteligência Artificial nos Sistemas Judiciários e seu Entorno, Estrasburgo: CEPEJ, 03 de dezembro de 2018. Disponível em https:// rm.coe.int/charte-ethique-fr-pour-publication-4-decembre-2018/16808f699b, acesso em 09 de julho de 2019.

EUROPA. Conselho da Europa. Comissão Europeia para a Eficácia da Justiça, Boîte à outils pour soutenir la mise en œuvre des Lignes Directrices sur la conduite du changement vers la cyberjustice, Estrasburgo: CEPEJ,13-14 de junho de 2019, pp. 14-15, disponível em https://rm.coe.int/cepej-boite-a-outils-cyberjustice-fr-cepej-2019-7/168094ef3d, acesso em 09 de julho de 2019.

FERNANDES TEIXEIRA, João de. Mentes e Máquinas, Porto Alegre: Artes Médicas, 1998.

FERNÁNDEZ, Gregorio. Panoramas de los sistemas expertos, In: CUENA, José (org.) Inteligencia Artificial: sistemas expertos, Madrid: Alianza Editorial, 1986, pp. 23-52.

FRANÇA. Conseil Constitucionnel. Décision no 2019-778 DC du 21 mars 2019, disponível em https://www.conseil-constitutionnel.fr/decision/2019/2019778DC. htm, acesso em 09 de julho de 2019.

GARCIA, Luiz Antônio Mendes. Perspectivas de Modernização da Justiça Brasileira, In: Escola Superior do Ministério Público do Paraná, 27 de junho de 2019, Curitiba: Ministério Público do Estado do Paraná. Disponível em: https://www.youtube. com/watch?v=JsAx7c0qwS4\&feature=youtu.be. Acesso em 29 de junho de 2019.

GUIMARÃES, Rodrigo Régnier Chemim. Atividade Probatória Complementar do Juiz como Ampliação da Efetividade do Contraditório e da Ampla Defesa no Novo Processo Penal Brasileiro. (Doutorado em Direito de Estado). Tese, Universidade Federal do Paraná, Curitiba, 2017, disponível em https://acervodigital.ufpr. br/bitstream/handle/1884/41025/R\%20-\%20T\%20-\%20RODRIGO\%20REGNIER\%20CHEMIM\%20GUIMARAES.pdf?sequence=2\&isAllowed=y, acesso em 06 de julho de 2019.

GUIMERÀ, R., SALES-PARDO, M.. Justice blocks and predictability of us supreme court votes. In: PloS One, 2011; 6(11):e27188. pmid:22096533, disponível em https://journals.plos.org/plosone/article?id=10.1371/journal.pone.0027188, acesso em 09 de julho de 2019. 
HEIDEGGER, Martin. Ser e Tempo. $2^{\mathrm{a}}$ ed., tradução de Márcia Sá Cavalcante Schuback, Petrópolis: Vozes, 2007.

KATZ, Daniel Martin; BOMMARITO, Michael J.; BLOCKMAN, Josh. A general approach for predicting the behavior of the Supreme Court of the United States, In: PLoS ONE, 12(4): e0174698. https://doi.org/10.1371/journal.pone.0174698, acesso em 09 de julho de 2019.

KAUFMAN, Dora. A Inteligência Artificial irá Suplantar a Inteligência Humana?, Barueri, SP: Estação das Letras e Cores, 2018.

KHALED JR., Salah H. A busca da verdade no processo penal: para além da ambição inquisitorial. São Paulo: Atlas, 2013.

LAGE-FREITAS, André; ALLENDE-CID, Héctor; SANTANA, Orivaldo; OLIVEIRA-LAGE, Lívia de. Predicting Brazilian court decisions. In: arXiv.org. Ithaca: Cornell University, 1905.10348v1 [cs.SI], 20 de abril de 2019. Disponível em https:// arxiv.org/pdf/1905.10348.pdf, acesso em 07 de setembro de 2019.

LOPES JR., Aury. Direito Processual Penal. 10a ed., São Paulo: Saraiva, 2013.

MARTIN, A. D.; QUINN, K.M.; RUGER, T.W.; KIM, P.T.. Competing approaches to predicting supreme court decision making, In: Perspectives on Politics, 2004; 2(4), pp. 761-767, disponível em https://www.cambridge.org/core/journals/ perspectives-on-politics/article/competing-approaches-to-predicting-supreme-court-decision-making/12CB7F54E411F9EA07DFADBB82196B0B, acesso em 09 de julho de 2019.

MATHEWS, Eric. Mente: conceitos-chave em filosofia, tradução de Michele Tse, Porto Alegre: Artmed, 2007.

MCCARTHY, John; MINSKY, Marvin L.; ROCHESTER, Nathaniel; SHANNON, Claude. A Proposal for the Dartmouth Summer Research Project on Artificial Intelligence, Agosto de 1955, disponível em http://jmc.stanford.edu/articles/dartmouth/ dartmouth.pdf, acesso em 05 de julho de 2019.

MCCARTHY, John. Ascribing Mental Qualities to Machines, In: Philosophical perspectives in artificial intelligence, RINGL, M (ed.), Atlantic Highlands, N.J.: Humanities Press, 1979, Disponível em http://jmc.stanford.edu/articles/ascribing/ ascribing.pdf, acesso em 05 de julho de 2019.

NIEVA FENOLL, Jordi. Inteligencia artificial y proceso judicial. Madrid: Marcial Pons, 2018.

NILSSON, Nils J. The Quest for Artificial Intelligence: a history of ideas and achievements. New York: Cambridge University Press, 2009. 
PLETSCH, Natalie Ribeiro. Formação da Prova no Jogo Processual Penal: o atuar dos sujeitos e a construção da sentença. São Paulo: IBCCRIM, 2007, pp. 65 e ss..

PRIMO, Alex; COELHO, Luciano Roth. A chatterbot Cybelle: a experiência pioneira no Brasil, In: RAMOS, Roberto (org.) Mídia, Textos e Contextos. Porto Alegre: Edipucrs, 2001, pp. 259-276.

PRIMO, Alex; COELHO, Luciano Roth. Comunicação e inteligência artificial: interagindo com a robô de conversação Cybelle. In: MOREIRA DOS SANTOS, Gil. O Direito Processual Penal, Porto: Asa Edições, 2002.

MOTTA, L. G. M. et al. (Eds.). Estratégias e culturas da comunicação, Brasília: Editora Universidade de Brasília, 2002, pp. 83-106.

RUGER, T. W.; KIM, P. T.; MARTIN, A. D.; QUINN, K. M.. The supreme court forecasting project: Legal and political science approaches to predicting supreme court decisionmaking, In: Columbia Law Review, , New York: Columbia Law School, 2004; 104(4), pp. 1150-1209, disponível em https://www.jstor.org/ stable $/ 4099370$ ?origin=crossref \&seq=1\#page_scan_tab_contents, aceso em 09 de julho de 2019.

RUSSELL, Stuart; NORVIG, Peter. Inteligência Artificial, $3^{\mathrm{a}}$ ed., tradução de Regina Célia Simille, Rio de Janeiro: Campus Elsevier, 2013.

SADIN, Eric. Intelligence Artificielle ou l'enjeu du siècle ( $\left.L^{\prime}\right)$ : Anatomie d'un antihumanisme radical. Paris: L’Echappée, 2018.

SEARLE, John R. Intencionalidade, tradução de Julio Fischer e Tomás R. Bueno. São Paulo: Martins Fontes, 2002.

SEARLE, John R. Minds, Brains and Programs, In: The Behavioral and Brain Sciences, 3, Cambridge University Press, 1980, pp. 417-457, disponível em https://www. law.upenn.edu/live/files/3413-searle-j-minds-brains-and-programs-1980pdf, acesso em 05 de julho de 2019.

SIMONS, G. L.. Introdução à Inteligência Artificial, tradução de Guilherme M. G. Dias Pires, Lisboa: Clássica Editora, 1986.

TASSE, Adel El; MILÉO, Eduardo Zanoncini; PIASECKI, Patrícia Regina. O Novo Sistema de Provas no Processo Penal. Comentários à Lei 11.690/08. Curitiba: Juruá, 2008.

TURING, Alan M.. Computing Machinery and Intelligence, In: Mind, A Quarterly Review of Psychology and Philosophy, New Series, vol. LIX, $\mathrm{n}^{\circ} 236$, Oxford University 
Press, outubro de 1950, pp. 433-460, disponível em https://phil415.pbworks. com/f/TuringComputing.pdf, acesso em 05 de julho de 2019.

VILHENA, Roberto. O seu futuro depende do passado, In: Casa do Saber, 2019. Disponível em: https://www.youtube.com/watch?v=El5NgfCrDpk\&feature=youtu. be, acesso em 01 de julho de 2019.

WARAT, Luis Alberto. O Direito e sua Linguagem, $2^{\mathrm{a}}$ ed., Porto Alegre: Sérgio Antonio Fabris Editor, 1995.

WITTGENSTEIN, Ludwig. Investigações Filosóficas, $6^{\mathrm{a}}$ ed., tradução de Marcos G. Nontagnoli, Petrópolis: Vozes, 2009.

\section{Informações adicionais e declarações dos autores (integridade científica)}

Declaração de conflito de interesses (conflict of interest declaration): o autor confirma que não há conflitos de interesse na realização das pesquisas expostas e na redação deste artigo.

Declaração de autoria e especificação das contribuições (declaration of authorship): todas e somente as pessoas que atendem os requisitos de autoria deste artigo estão listadas como autores; todos os coautores se responsabilizam integralmente por este trabalho em sua totalidade.

Declaração de ineditismo e originalidade (declaration of originality): o autor assegura que o texto aqui publicado não foi divulgado anteriormente em outro meio e que futura republicação somente se realizará com a indicação expressa da referência desta publicação original; também atesta que não há plágio de terceiros ou autoplágio. 
Dados do processo editorial

(http://www.ibraspp.com.br/revista/index.php/RBDPP/about/editorialPolicies)

- Recebido em: 10/07/2019

- Controle preliminar e verificação de plágio: 12/07/2019

- Avaliação 1: 12/07/2019

- Avaliação 2: 25/07/2019

- Avaliação 3: 01/08/2019

- Decisão editorial preliminar: 27/08/2019

- Retorno rodada de correções: 09/09/2019

- Decisão editorial final: 20/09/2019

\section{COMO CITAR ESTE ARTIGO:}

GUIMARÃES, Rodrigo R. C. A Inteligência Artificial e a disputa por diferentes caminhos em sua utilização preditiva no processo penal. Revista Brasileira de Direito Processual Penal, Porto Alegre, vol. 5, n. 3, p. 1555-1588, set./dez. 2019. https://doi.org/10.22197/rbdpp.v5i3.260

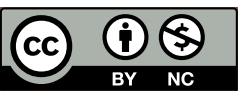

Esta obra está licenciada com uma Licença Creative Commons Atribuição-NãoComercial 4.0 Internacional. 